\title{
Unraveling the mystery of the rounder, sweeter chocolate bar
}

\author{
Charles Spence
}

\begin{abstract}
The new rounded Cadbury's Dairy Milk chocolate bar has got some consumers irate because they say it tastes sweeter than the original, more rectangular bar. The company says the formulation has not changed. Who is right? I suggest that this furore can perhaps be explained with reference to the literature on shape symbolism. People are known to associate sweetness with roundness and angularity with bitterness and, hence, making a traditionally rectangular food rounder may be expected to alter the perceived taste by priming notions of sweetness in the mind of the consumer.
\end{abstract}

Those living in the UK may well have come across the curious case of the new Cadbury's chocolate bar (see Figure 1). This story hit the headlines recently (for example, see [1]). Apparently, consumers have been writing and phoning-in in droves (though exact numbers are understandably hard to come by) to voice their concern about what has happened to their much-loved Dairy Milk bar. In particular, many of them have been complaining that the new, rounder format bar tastes 'too sweet'. Not that the punters are all that happy about paying the same price for a bar that now weighs in at $4 \mathrm{~g}$ less than the original either, of course.

Is this just another example of the marketers and focus groups getting it wrong in terms of predicting the consumer preference for new product extensions? Perhaps not. In fact, the plot thickens when one reads the reply from Tony Bilsborough of Mondelez International, the wing of Kraft that runs Cadbury. He has been quoted as saying that: "We have been very clear and consistent that we have not changed the recipe of the much-loved Cadbury Dairy Milk, although it's certainly true that we changed the chunk last year from the old, angular shape to one that's curved" [1]. So what is going on here? Who is telling the truth and who is telling 'porkie pies'? Well, I would like to argue that, counterintuitive though it may seem, both sides may have truth on their side in this particular debate.

Correspondence: charles.spence@psy.ox.ac.uk

Crossmodal Research Laboratory, Oxford University, OXI 3UD, Oxford, UK
The mystery of the chocolate bar that has become too sweet without its formulation having changed starts to make sense once one delves into the recent literature on shape symbolism and crossmodal correspondences, as they apply to the world of taste and flavor (see [2,3] for reviews). Surprising though it may seem, people make consistent matches between shape properties (such as angularity and roundness as captured by the shapes anchoring the line scale shown in Figure 2) and various tastes, flavor, aromas, and oral-somatosensory textures in food and drink $[4,5]$. As far as chocolate goes, Ngo and colleagues [6] have demonstrated that people match the sweeter taste of milk chocolate with rounder shapes while pairing the bitter taste of dark chocolate with shapes that are more angular instead (see Figure 2). The generalization that has now been documented across a range of food and beverage products is that sweetness is associated with roundness while bitterness is associated with angularity.

To date, sweetness has been paired with roundness in a range of different foodstuffs ranging from fruit juices to yoghurts and from milk chocolate to fruit juices. By contrast, angularity has been matched with bitterness, carbonation, and sourness in beers, sparkling waters, fruits, fruit juices, dark chocolates, salt and vinegar crisps, and so on (see [3-6] for reviews). When it comes to the question of where these shape symbolic associations come from in the first place, one plausible suggestion that has been made is that angularity, bitterness, and carbonation might be associated because they all have some link to danger. Angular shapes are potentially weapons, and our brain's fear circuits have been shown to light up within a few 10's 


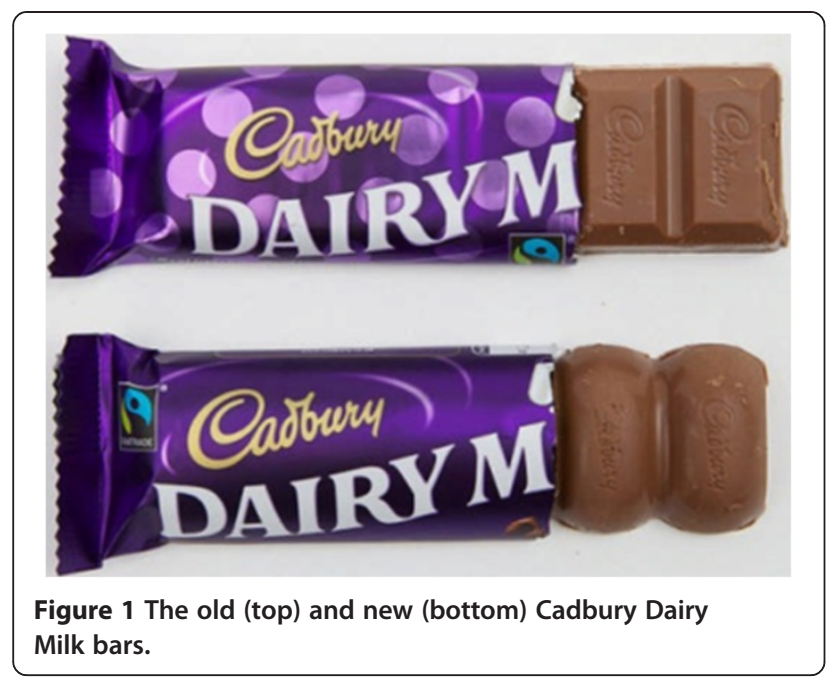

or 100's of milliseconds of seeing an angular shape. Bitterness and carbonation are also, evolutionarily at least, danger signals that would have been associated with foods that were potentially poisonous (bitterness) or overripe (carbonation). By contrast, people typically exhibit a much more positively valenced response to both sweetness and rounded shapes [3]. However, further research will likely be needed before a clear answer as to the origins of these mysterious and intriguing effects is uncovered.

Back in the 1960s, Madison Avenue's marketing magicians Cheskin [7] and Dichter [8] already knew that "Round = Sweet" when it comes to the shapes that should be used on the outside of product packaging (see also [9]). Given that Cheskin was working on the coloring of the 7-Up can back in the 1950s, one can only guess as to whether the distinctive red circle that forms such a central part of the logo might not have resulted from just such an intervention. What is new is the intriguing prediction coming out of the recent literature on shape symbolism research that if one changes the actual shape in which a food is presented then it can change how the consumer will rate its taste. For instance, Jools Simner has conducted intriguing research showing that exactly the same food will be rated as tasting significantly more bitter if served in an angular shaped format, whereas serving the very same food in a rounded form, think a sphere, can help enhance perceived sweetness slightly (a summary of Simner's research findings can be found in $[4,5])$.

However, to date, all of the research on changing the shape of food (not to mention the plateware [10]) on taste and flavor perception has been conducted on a small scale in the laboratory or at gastronomy events such as the Edinburgh Science Festival. Critics are often worried that the subtle effects of shape on taste, while perhaps demonstrable in the laboratory in, say, a withinparticipants experimental design, would simply get lost in the noise of our everyday interactions with food. Up until now, the academic researcher has been unable to counteract such a claim. It is almost impossible to convince an international food company to conduct such large scale studies in the marketplace with one of their own products. And should the researcher be successful in convincing a company to undertake such a study out there in the real world, it will be highly unlikely to win the next battle in terms of convincing the company concerned to allow publication of the results for all their competitors to see. That is why the furore surrounding the new 'sweeter' Dairy Milk bar is so very interesting.

If we take the Dairy Milk man at his word (and whyever should we not?), and if the complainants can be taken to be representative of the consumer response more generally, then what we have here is really like the ideal real-world experiment. The hypothesis being tested is whether changing the shape of a much-loved real food product (in this case, a chocolate bar) to make it rounder (and less angular), without introducing any change to the formulation of the product, can change people's rating of its taste. The evidence would appear to be unequivocally

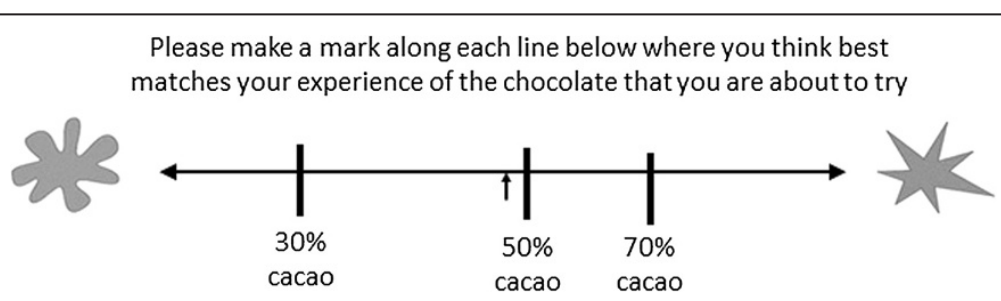

Figure 2 The shape symbolism of chocolate. The figure shows the shape symbolism scale that has often been used by researchers working in this area. People are given a food or beverage product to taste or smell and are requested to place a mark somewhere along the scale that, in some sense, 'matches' the taste, flavor, aroma, or texture of what they are experiencing (that is, tasting and smelling). Note here that we are not talking about the shape that the food normally has, but rather the more abstract shape that feels like it goes with the sensory qualities of the foodstuff being evaluated. Note also that the position of the angular and rounded labels on the scale are normally reversed on half of the trials to rule out any form of spatial bias in these tasks. Superimposed over the scale are the schematic results of a study by Ngo and colleagues [6] demonstrating that people match sweeter milk chocolate (with a lower cocoa content) with a more rounded shape, while matching the more bitter dark chocolate with a more angular shape instead. The small arrow indicates mid-point of scale. 
in the affirmative, thus backing up the better controlled, but much smaller scale, laboratory studies that have been published to date $[4,5]$.

Paul Young, an award-winning London-based chocolatier, puts his finger on it when he says that "the rectangular chunks of the old bars were integral to the taste of Dairy Milk" [1]. On the one hand, then, I would suggest that the big food companies and chefs really ought to sit-up and take note; changing the shape of the food really can change its taste! This can happen both as a result of shape symbolic priming of taste qualities as stressed here, but possibly also as a result of the different sensory experience of the rounder chocolate within the oral cavity itself [11]. What is more, such insights can, theoretically at least (and if managed appropriately), be used to help promote healthy eating [12]. How so? Well, in the Dairy Milk case, it should have been possible to combine the change to the new 'sweeter' shape of the product with a slight reduction in sugar content of the chocolate bar, and leave the consumer's overall perception of sweetness unchanged. Had Cadbury's done this then they might have succeeded in keeping everyone happy. Innovating in terms of the shape of their food product, while making their confectionary offering a little less unhealthy: surely a win-win situation.

\section{Competing interests}

The author declares that he has no competing interests.

Received: 20 September 2013 Accepted: 21 October 2013

Published: 14 November 2013

\section{References}

1. Martin A: Revolt over Cadbury's 'rounder, sweeter' bars: Not only has the classic rectangle shape of a Dairy Milk changed, customers say they are more 'sugary' too. UK: DailyMail Online, 2013. [http://www.dailymail.co.uk/news/article2421568/Revolt-Cadburys-rounder-sweeter-bars-Not-classic-rectangle-shapeDairy-Milk-changed-customers-also-sugary.html]

2. Spence C: Crossmodal correspondences: a tutorial review. Atten Percept Psychophys 2011, 73:971-995.

3. Spence C: Managing sensory expectations concerning products and brands: capitalizing on the potential of sound and shape symbolism. J Consum Psychol 2012, 22:37-54.

4. Spence C, Deroy O: On the shapes of tastes and flavours. Petits Propos Culinaires 2012, 97:75-108.

5. Spence C, Deroy O: Tasting shapes: a review of four hypotheses. Theoria et His Sci. in press.

6. Ngo M, Misra R, Spence C: Assessing the shapes and speech sounds that people associate with chocolate samples varying in cocoa content. Food Qual Prefer 2011, 22:567-572.

7. Cheskin L: Secrets of Marketing Success: An Expert's View on the Science and Art of Persuasive Selling. New York: Trident Press; 1967.

8. Dichter E: The strategy of selling with packaging. Package Eng Mag 1971:16a-16c.

9. Gal D, Wheeler SC, Shiv B: Cross-Modal Influences on Gustatory Perception; 2007. Available at SSRN: http://ssrn.com/abstract=1030197.
10. Piqueras-Fiszman B, Alcaide J, Roura E, Spence C: Is it the plate or is it the food? Assessing the influence of the color (black or white) and shape of the plate on the perception of the food placed on it. Food Qual Prefer 2012, 24:205-208.

11. Roxby P: Chocolate Craving Comes from Total Sensory Pleasure. UK: BBC News; 2013 [http://www.bbc.co.uk/news/health-23449795]

12. Marteau TM, Hollands GJ, Fletcher PC: Changing human behaviour to prevent disease: the importance of targeting automatic processes. Science 2012, 337:1492-1495.

doi:10.1186/2044-7248-2-28

Cite this article as: Spence: Unraveling the mystery of the rounder, sweeter chocolate bar. Flavour 2013 2:28.

\section{Submit your next manuscript to BioMed Central and take full advantage of:}

- Convenient online submission

- Thorough peer review

- No space constraints or color figure charges

- Immediate publication on acceptance

- Inclusion in PubMed, CAS, Scopus and Google Scholar

- Research which is freely available for redistribution 